\title{
Procedures for risk assessment of critical slant prevention ergonomic work stations: a case study
}

\author{
Jandecy Cabral Leite ${ }^{2}$, Getúlio Lima de Queiroz ${ }^{1}$, Jorge de Almeida Brito Junior ${ }^{2}$, Enily Vieira do Nasicmento ${ }^{1}$, Marcello \\ Fonseca Pires ${ }^{1}$ \\ jandecycabral@hotmail.com, getuliolima_am@hotmail.com,jorgebritojr@gmail.com, enilyvieira@gmail.com \\ mclfonseca1@hotmail.com
}

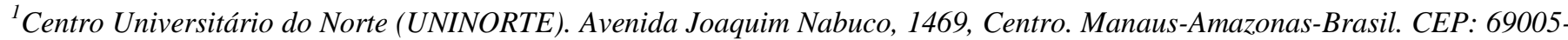
290. Fone: +55 (92) 32125000 .

${ }^{1,2}$ Instituto de Tecnologia Galileo da Amazônia (ITEGAM). Avenida Joaquim Nabuco, 1990. Centro. Manaus - Amazonas- Brasil. CEP: 69020-031. Fone: +55 (92) $35846145 e+55$ (92) 32482646.

\begin{abstract}
Quality of life $(\mathrm{QV})$ is directly related to the quality of work life $(\mathrm{QWL})$, as it is in the workplace that individuals occupy most of the time. Therefore, states that job satisfaction, daily hours of work, remuneration, conditions of the physical environment, the opportunity to advance, among other factors, are being discussed and studied to make the most satisfying and less harmful to health of employees working conditions. The aim of this study is to identify risk factors that affect the performance of the activities of the production chain partners LTDA Amapoly Industry and Trade, and the impact of predisposing aspects of occupational diseases related to work. This is a qualitative and quantitative study, is characterized by the use of precision measuring outcomes intended to prevent distortion of analysis and interpretation, allowing, therefore, a degree of certainty as to the deductions and qualitative in which the researcher to obtain "measures" with greater internal validity because unstructured observations allow us to know details that structured instruments (questionnaires) can not achieve. From a descriptive approach that allowed discover and classify the relationship between variables and discover the characteristics of the phenomenon of investigation. Results identified the risk factors affecting the performance of the activities of contributors, and the impact of predisposing aspects of TME. The study confirmed the importance of ergonomics in the investigation of issues related to occupational diseases, namely the causal factors of musculoskeletal disorders, and no prevention among at-risk populations is paramount to first, there is an awareness by both employers and employees.
\end{abstract}

Keywords: Biomechanics, Ergonomics, Jobs, Analysis of occupational risks.

\section{Procedimentos para avaliação de risco de prevenção cunho crítico estações de trabalho ergonômicas: um estudo de caso}

\begin{abstract}
RESUMO
A qualidade de vida (QV) está diretamente relacionada com a qualidade de vida no trabalho (CVT), quando você considera que as pessoas na maioria das vezes eles estão engajados em seu trabalho. Portanto, podemos dizer que a satisfação no trabalho, jornada diária de trabalho, remuneração, condições do ambiente físico, a oportunidade de avançar, entre outros fatores, são discutidos de modo que a atividade de trabalho cada dia mais gratificante e menos prejudicial para a saúde dos trabalhadores. O objetivo deste estudo é identificar fatores de risco que afetam o desempenho das atividades dos empregados da cadeia de produção Amapoly LTD Indústria e Comércio e do impacto sobre as doenças ocupacionais relacionados ao trabalho. Um estudo qualitativo e quantitativo, caracterizado pela utilização dos resultados de medição de precisão destinada a evitar distorções da análise e interpretação, permitindo um grau de certeza quanto às avaliações efetuadas. A partir de uma abordagem descritiva, é possível descobrir e classificar a relação entre variáveis e descobrir as características do fenômeno da investigação. Os resultados identificaram os fatores de risco que afetam o desempenho das atividades dos empregados e o impacto dos aspectos de predisposição a doenças, lesões músculo-esqueléticas (LME). O estudo confirmou a importância da ergonomia na investigação de questões relacionadas com doenças profissionais.
\end{abstract}

Palavras-chave: biomecânica, ergonomia, Postos de trabalho, Prevenção de Riscos ergonômicos.

\section{Introdução}

As condições de trabalho podem ser caracterizadas como os meios pelos quais as colaboradoras desenvolvem suas atividades no Pólo Industrial de Manaus (PIM), não importando quais sejam elas, porém são elas que irão determinar o sucesso ou insucesso da produtividade, bem como o bem estar das colaboradoras. Dentre as condições de trabalho, considera-se os aspectos

ITEGAM - JETIA Vol. 01, Nº 02. Junho de 2015. Manaus - Amazonas, Brasil. ISSN 2447-0228 (ONLINE). 
ambientais (ruído, temperatura, luminosidade, vibração, qualidade do ar), os aspectos técnicos (máquinas, layout, mobiliário) e, ainda, os aspectos organizacionais (divisão do trabalho, o número e a duração das pausas, trabalho em turnos, ritmo de trabalho), as quais das colaboradoras está inserido no meio produtivo do PIM.

Sendo assim, nas últimas décadas, tem-se observado de forma progressiva a substituição da prestação de serviços braçais, por equipamentos através da instalação de sistemas automatizados e informatizados. Para isso, as colaboradoras da Amapoly Indústria e Comercio estão sendo submetidas a uma adaptação súbita frente às solicitações de novas condições de trabalho que, muitas vezes, implica na manutenção de posturas estafantes, levando o indivíduo permanecer a maior parte do tempo em pé.

Com as modificações realizadas subitamente no ambiente de trabalho, as atividades tornam-se cada vez mais específicas, exigindo grande esforço físico e mental das colaboradoras, que se deve a não disponibilidade de tempo para adaptação do organismo a este desenvolvimento, tornando-se justificável o número cada vez mais crescente de doenças ocupacionais.

Para Cruz (2001), as atuais transformações no mundo do trabalho e os impactos da reestruturação produtiva parecem ter aumentado as proporções das implicações sobre a saúde das colaboradoras, ampliando e tornando mais complexa a avaliação dos sintomas de dor, desconforto físico e psicológico. Muitas são as atividades realizadas pelo homem e descritas na literatura que são propensas a desenvolver distúrbios músculo-esqueléticos e/ou Doenças Ocupacionais Relacionada ao Trabalho (DORT) e as Lesões de Esforços Repetitivos (LER), está inclusa a atividade: fabricação de lonas e coberturas, a qual destina-se esta pesquisa.

Nos estudos sobre os DORT, é comum atribuir uma multicausalidade ao aparecimento da doença, todavia, novas implementações ergonômicas nos postos de trabalho, de nada valem se as colaboradoras não estiverem adaptadas às condições oferecidas e, sobretudo, se não for instituído e cumprido os parâmetros organizacionais, o que representa grande importância na qualidade da realização da atividade. Neste contexto, Filho \& Barreto (1998), descrevem que, as LER, constitui-se um problema de saúde pública, com repercussões sociais e econômicas. Ressaltam que para cada categoria profissional, existe uma característica particular de exigência mental e motora, e devido a tais exigências, há locais mais suscetíveis e o que irá determinar, é a alta exposição e intensidade do trabalho.

No caso das colaboradoras de produção da Amapoly, são diversos os fatores de riscos, desde a postura em que realizam suas atividades, até o manuseio de equipamentos e ferramentas usuais que sobrecarregam principalmente os membros superiores; além das rotações de tronco. A realização destas atividades por tempo prolongado trará algum tipo de distúrbio em alguma região do corpo.

Nas organizações, e mais precisamente, nos setores em que exijam a longa permanência numa mesma postura, ou seja, sentada ou em pé, consequentemente as colaboradoras passam adotar posturas que lhe pareça confortável, mas que nem sempre é a ideal ou biomecanicamente adequada para o desenvolvimento de determinadas atividades, ocasionando, então, a ocorrência de algias musculares que no início podem passar despercebidas, todavia, com o decorrer do tempo, a dor tende a aumentar podendo tornar-se motivo de afastamento do trabalho ou em casos extremos, de grande incapacidade funcional. Também, a combinação de fatores individuais como o biótipo, idade, condições sócio-econômicas, associado a instalações físicas e posturais inadequadas, são mecanismos contribuintes para o aparecimento de disfunções funcionais e dores musculares. A este respeito, Iida (2010), comenta que esforços repetitivos, trabalho estático, esforço físico intenso, ritmos intensos de trabalho e posturas inadequadas estão presentes na maioria das situações de trabalho, das diversas atividades profissionais, sendo causas para o aparecimento ou agravamento de lesões, principalmente no sistema músculo-esquelético.

\section{Referencial Bibliográfica \\ 2.1 Aspectos Gerais sobre a Ergonomia}

Inicialmente a aplicação da ergonomia se fazia quase que exclusivamente na indústria e se concentrava no binômio homem-máquina. Hoje é bem mais abrangente, estudando sistemas complexos, onde dezenas ou até centenas de elementos interagem entre si, abarcando quase todos os tipos de atividades humanas. A ergonomia é o estudo da adaptação do trabalho para o homem. O trabalho aqui tem uma acepção bastante ampla, abrangendo não apenas aquelas máquinas e equipamentos utilizados para transformar os materiais, mas também toda a situação em que ocorre o relacionamento entre homem e seu trabalho. Isso envolve não somente o ambiente físico, mas também os aspectos organizacionais de como esse trabalho são programados e controlados para produzir os resultados desejados.

Observa-se que a adaptação sempre ocorre do trabalho para o homem. A recíproca nem sempre é verdadeira. Ou seja, é muito mais difícil adaptar o homem ao trabalho. Isso significa que a ergonomia parte do conhecimento do homem para fazer o projeto do trabalho, ajustando-o às capacidades e limitações humanas. $\mathrm{O}$ termo "saúde" é a expressão das condições sociais, culturais e históricas das coletividades em que o trabalho desempenha papel crucial. Para Brito (2000), o trabalho realizado na sociedade é completamente determinado pelas relações entre os poderes sociais, econômicos e políticos. Segundo Leite (2004), "para realizar o seu objetivo, a ergonomia estuda diversos aspectos do comportamento humano no trabalho e outros fatores importantes para o projeto de sistemas de trabalho, que são": O homem características físicas, fisiológicas, psicológicas e sociais do trabalhador; influência do sexo, idade, treinamento e motivação; Máquina - entende-se por máquina todas as ajudas materiais que o homem utiliza no seu trabalho, englobando os equipamentos, ferramentas, mobiliários e instalações; Ambiente - estuda as características do ambiente físico que envolve o homem durante o trabalho, como a temperatura, ruídos, vibrações, luz, cores, gases e outros; Informação - refere-se às comunicações existentes entre os elementos de um sistema, a transmissão de informações, o processamento e a tomada de decisões; Organização - é a conjugação dos elementos acima citados no sistema produtivo, estudando aspectos como horários turnos de trabalho e informação de equipes; e consequência do trabalho aqui entra mais as questões de controles como tarefas de 
inspeções, estudo dos erros e acidentes, além dos estudos sobre gastos energéticos, fadiga e "stress" (IIDA, 2010).

\subsection{Algumas Definições para Ergonomia}

$>$ IIDA (2010) define a Ergonomia como o estudo da adaptação do trabalho ao homem. Neste contexto, o trabalho tem uma acepção bastante ampla, abrangendo não apenas máquinas e equipamentos utilizados, mas também toda a situação que envolve o homem e seu trabalho, ambiente físico, aspectos organizacionais, programação e controle para produzir os resultados desejados.

$>$ MONTMOLLIN, M. - A Ergonomia é a tecnologia das comunicações homem-máquina (1971).

$>$ GRANDJEAN, E. - A Ergonomia é uma ciência interdisciplinar. Ela compreende a fisiologia e a psicologia do trabalho, bem como a antropometria é a sociedade no trabalho. O objetivo prático da Ergonomia é a adaptação do posto de trabalho, dos instrumentos, das máquinas, dos horários, do meio ambiente às exigências do homem. A realização de tais objetivos, ao nível industrial, propicia uma facilidade do trabalho e um rendimento do esforço humano (1998).

$>$ LEPLAT, J - A Ergonomia é uma tecnologia e não uma ciência, cujo objeto é a organização dos sistemas homens-máquina (1972).

$>$ MURREL, K.F. - A Ergonomia pode ser definida como o estudo científico das relações entre o homem e o seu ambiente de trabalho (1965).

$>$ SELF - A Ergonomia reúne os conhecimentos da fisiologia e psicologia, e das ciências vizinhas aplicadas ao trabalho humano, na perspectiva de uma melhor adaptação ao homem dos métodos, meios e ambientes de trabalho.

$>$ WISNER - A Ergonomia é o conjunto de conhecimentos científicos relativos ao homem e necessários à concepção de instrumentos, máquinas e dispositivos que possam ser utilizados com o máximo de conforto e eficácia (1997).

\subsection{Objeto e Objetivo da Ergonomia}

Se, para um certo número de disciplinas, o trabalho é o campo de aplicação ou uma extensão do objeto próprio da disciplina, para a ergonomia o trabalho é o único possível de intervenção. A ergonomia tem como objetivo produzir conhecimentos específicos sobre a atividade do trabalho humano. O objetivo desejado no processo de produção de conhecimentos é o de informar sobre a carga do trabalhador, sendo a atividade do trabalho específica a cada trabalhador. O procedimento ergonômico é orientado pela perspectiva de transformação da realidade, cujos resultados obtidos irão depender em grande parte da necessidade da mudança. Mesmo que o objetivo possa ser diferente de acordo com a especialização de cada pesquisador, o objeto do estudo não pode ser definido a priori, pois sua construção depende do objetivo da transformação.
Em ergonomia o objeto sobre o qual pretende-se produzir conhecimentos, deve ser construída por um processo de decomposição/recomposição da atividade complexa do trabalho, que é analisada e que deve ser transformada. O objetivo é ocultar o mínimo possível à complexidade do trabalho real. Quanto mais ergonomia aprofunda o seu questionamento sobre a realidade, mais ela é interpelada por ela mesma. Para Leite (2004), a ergonomia tem como objetivo produzir conhecimentos específicos sobre a atividade do trabalho humano. O objetivo desejado no processo de produção de conhecimentos é o de informar sobre a carga da colaboradora, sendo a atividade do trabalho específica a cada trabalhador.

\subsection{Métodos e Técnicas}

A Ergonomia utiliza métodos e técnicas científicas para observar o trabalho humano. A estratégia utilizada pela Ergonomia para apreender a complexidade do trabalho é decompor a atividade em indicadores observáveis (postura, exploração visual, deslocamento). A partir dos resultados iniciais obtidos e validados com os operadores, chega-se a uma síntese que permite explicar a inter-relação de vários condicionantes à situação de trabalho. Como em todo processo científico de investigação, a espinha dorsal de uma intervenção ergonômica é a formulação de hipóteses. Para Nogueira (2005) "o pesquisador trabalha em geral a partir de uma hipótese, é isso que lhe permite ordenar os fatos". São as hipóteses que darão o status científico aos métodos de observação nas atividades do homem no trabalho.

A organização das observações em uma situação real de trabalho é feita em função das hipóteses que guiam a análise, mas também, segundo Grandjean (1998), em função das imposições práticas ou das facilidades de cada situação de trabalho. Os comportamentos manifestáveis do homem são frequentemente observáveis pelos ergonomistas, como por exemplo: Os deslocamentos dos operadores - esses podem ser registrados a partir do acompanhamento dos percursos realizados pelo operador em sua jornada de trabalho. Para Nascimento \& Moraes (2000), a Ergonomia é uma ciência que, independente da sua linha de atuação, estratégia e/ou métodos de estudos aplicados, objetiva solucionar problemas da relação entre homem, máquina, equipamento, ferramentas, programação de trabalho, instruções e informações, resolvendo conflitos entre o homem e a tecnologia aplicada ao seu trabalho.

\subsection{Aspectos Organizacionais na Ergonomia}

Além das definições encontradas na literatura específica sobre a Ergonomia, constata-se a grande relevância dada aos aspectos organizacionais, porém mesmo o ambiente estando em plenas condições ergonômicas no que se refere ao mobiliário, nada adiantará se não houver uma organização eficaz.

Essa eficácia refere-se à descoberta e reorganização de alguns aspectos imprescindíveis como, a melhor maneira de executar um serviço, a utilização dos recursos mais apropriados, instruções e treinamentos sobre o uso correto e a manutenção dos equipamentos necessários. Todos esses itens quando analisados e 
realizados de forma inadequada, são fatores desencadeantes do estresse físico e psíquico do trabalhador. Para Wisner (1997) os principais fatores desencadeantes de estresse físico e psíquico são os seguintes: trabalho assalariado tornou-se regra geral nas sociedades; trabalho assalariado está sujeito a um contrato de trabalho, em cujos termos a organização do trabalho é determinada pela empresa; volume, a estabilidade e a qualidade da produção parecem facilmente controlados por um dispositivo organizacional muito complexo e preciso; tempo em que se passa no trabalho, a pregnância dessa parte da vida, a concentração de poder na empresa e o caráter artificial dos atuais postos de trabalho às vezes estão na origem de riscos para a saúde, mas fornecem também os meios de prevenir de forma eficaz eventuais dificuldades.

\subsection{Aspectos Biomecânicos Relacionados ao Trabalho}

Para a melhor compreensão sobre os mecanismos posturais e sua manutenção perante as situações exigidas no trabalho e na vida cotidiana, Iida (2003), aponta as interações entre o trabalho e o homem sob o ponto de vista dos movimentos músculoesqueléticos envolvidos. O autor analisa a questão das posturas corporais no trabalho e a aplicação de forças. Faz referência ao manuseio de produtos e instalações físicas, que se forem inadequadas e realizadas biomecanicamente incorretas, podem ser motivo para o surgimento de tensões musculares, dores e fadiga. Dul e Weerdmeester (2004), descreve os princípios mais importantes da biomecânica para a Ergonomia. Ressalta que as articulações devem ocupar uma posição neutra; conservar pesos próximos ao corpo; evitar curvar-se para frente; evitar inclinar a cabeça; evitar torções de tronco e movimentos bruscos que produzem picos de tensão; alternar posturas e movimentos; restrinjir a duração do esforço muscular contínuo; prevenir a exaustão muscular e opção por pausas curtas e frequentes. $\mathrm{O}$ movimento humano é um sistema de comportamento físico marcado por normas, regras e convenções que, adapta as condições em respostas anátomo-fisiológicas e biomecânicas do corpo e, através de sua estrutura biológica, permite a produção de força através da contração muscular, transformando o corpo num sistema independente possibilitando o movimento. A biomecânica utiliza as leis da física e conceitos de engenharia para descrever os diversos movimentos realizados pelo corpo humano durante toda a atividade, seja ela profissional ou atividades normais de vida diária. Chaffin et al., (2001) definem a biomecânica como uma ciência multidisciplinar, que deriva dos conhecimentos das ciências físicas, biológicas e comportamentais, além dos conhecimentos sobre a engenharia.

Quando um músculo está contraído, segundo Pereira (2000), há um aumento da pressão interna, provocando um estrangulamento dos capilares, isto faz com que o sangue deixe de circular nos músculos contraídos, quando estes atingem $60 \%$ da contração máxima. Este fenômeno não ocorre se a contração atingir apenas $15 \%$ ou $20 \%$ da força máxima do músculo, ou seja, a circulação continua de forma satisfatória. Desta forma, pode-se entender que, de um músculo com má nutrição sanguínea surge à fadiga rapidamente. O ideal é a alternância, ou seja, oferecer condições em que o músculo contraia e relaxe de forma alternada, onde ele próprio trabalhe como uma bomba sanguínea e, consequentemente, receba maior quantidade de oxigênio, tornando-se, assim, mais resistente à fadiga. Comentando a respeito do trabalho físico muscular, Grandjean (1998), relata que a fisiologia do trabalho distingue duas formas de esforço muscular, quais sejam, o trabalho muscular dinâmico e trabalho muscular estático.

As posturas constituem um reflexo de uma série de imposições da atividade a ser realizada. A postura é um suporte à atividade gestual do trabalho e um suporte às informações obtidas visualmente. A postura é influenciada pelas características antropométricas do operador e características formais e dimensionais dos postos de trabalho. Para Knoplich (1996), estes constituintes anatômicos são as vértebras, discos, articulações e músculos. Ressalta, ainda, que a postura estática é o equilíbrio do organismo do homem na posição parada (de pé, sentado ou deitado), numa situação que não cause nenhum dano às estruturas, e não produza dor quando essa posição for mantida durante muito tempo.

Santos (1996) caracteriza a postura "padrão" como uma postura de alinhamento esquelético refinado em um arranjo relativo das partes do corpo, em estado de equilíbrio que protege as estruturas de apoio do corpo contra lesão ou deformidade progressiva. A postura é o arranjo relativo das partes do corpo. A boa postura promove o equilíbrio entre as estruturas de suporte do organismo, possibilitando que o sistema músculo-esquelético desempenhe suas funções com maior eficiência. Por oclusão, a má postura é aquela em que o relacionamento entre as várias partes do corpo induz a uma agressão às estruturas de suporte, promovendo fadiga e aumento do processo degenerativo. $\mathrm{Na}$ concepção de Barreira (1989), as diversas posturas (em pé, deitado, sentado, inclinado à frente, agachado) podem, durante o repouso e o trabalho, ser realizadas em condições mais adequadas, para que os músculos possam desempenhar suas funções mais eficientemente. Em contrapartida, descreve que a má postura consiste numa falta de relacionamento das várias partes que o corpo assume na preparação do próximo movimento.

São diversas as características de trabalho que têm uma influência direta sobre a postura do executante às quais, Laville (1977), descreve como as principais: Exigências visuais: precisão de detalhes que devem ser percebidos, o que determinará a distância olho - tarefa; plano no qual estão situados, o que determinará o eixo visual e, portanto, a orientação da cabeça; amplitude do espaço que deve ser inspecionado, o que determinará a amplitude de movimento da cabeça; Exigências de precisão de movimentos: um movimento preciso necessita, em geral, de imobilização dos segmentos corporais que não participam do movimento. A precisão é aumentada quando o movimento é executado diante do plano frontal do corpo e bastante próximo ao eixo corporal; Exigências da força a ser exercida: resistência dos comandos, pesos dos instrumentos, cargas e deslocar.

Durante a jornada de trabalho, o profissional assume posturas corporais específicas para o melhor desenvolvimento de suas atividades, adotando posturas antifisiológicas que segundo Coury (1995), é devido à imposição de cargas físicas intensas ou 
a não observância de padrões ergonômicos nos postos de trabalho. Pereira (s/d) relata que o trabalho em pé apresenta-se ideal sob o ponto de vista do gasto energético, porém, promove distúrbios osteomusculares e contribui para o sedentarismo. A posição sentada dificulta o retorno venoso e linfático, pois a pressão na parte posterior das coxas funciona como importante obstáculo.

\subsection{Diferentes Terminologias Utilizadas}

Encontra-se na literatura específicas várias denominações a respeito das afecções que podem acometer tanto a estrutura óssea como também as partes moles (tendões, sinóvias, músculos, nervos, ligamentos), afecções estas que resultam de dor, inflamação e distúrbios neurovasculares, podendo levar o indivíduo à degradação de sua funcionalidade e até desequilíbrio emocional.

Para Nascimento \& Moraes (2000) conceituam algumas denominações que dizem respeito às afecções relacionadas ao trabalho como: LTC: (lesão por trauma cumulativo), termo pouco citado; DMO: (distúrbio músculo-esquelético ocupacional), também pouco referido; LER: (lesão por esforços repetitivos), termo mais conhecido e citado nas literaturas, porém não o mais correto para designar as doenças ocupacionais; DORT: (distúrbio osteomuscular relacionado ao trabalho), denominação mais recente e está sendo adotada oficialmente pela Norma do INSS, em vigor desde o segundo semestre de 1997. Algumas terminologias se classifica quanto ao que seria ou não uma doença ocupacional ou relacionada ao trabalho. Salienta que, quando a exposição a um risco no local de trabalho associase diretamente a um resultado à saúde, o termo "doença ocupacional" é apropriado. Quando no trabalho existem múltiplos fatores associados à doença e até quando as exposições não ocupacionais podem produzi-la, deve ser adotado o termo "doença relacionada ao trabalho". O termo "doença" é apropriado quando o resultado para a saúde apresenta um claro processo ou agente patológico. O termo "distúrbio" é corretamente utilizado quando alguns dos resultados são de patogênese incerta, podendo consistir de sintomas sem sinais óbvios. Descreve, ainda que, no trabalho, o sistema osteomuscular sofre a atuação de uma ampla variedade de fatores que, dependendo da força e duração, podem implicar em alterações na saúde osteomuscular, sendo que aqueles que agravam os distúrbios osteomusculares são conhecidos como fatores de risco para os DORT.

Para Cruz et al. (2001), os avanços nos estudos dos grupos de patologias têm identificado que o esforço repetitivo não é o único fator causal. Aliados a este, associa-se uma série de fatores que contribuem para o surgimento desta patologia, que são inerentes à organização do trabalho, como o ritmo acelerado e a jornada prolongada de trabalho, condições ambientais inadequadas. Além disso, pode-se considerar, os fatores psicossociais do trabalho, como conflitos no relacionamento profissional com colegas e chefias. Por este motivo foi criada a denominação dos DORT, como sendo a mais recente e mais abrangente, pois as doenças ocupacionais estão diretamente relacionadas à situação do trabalho, englobando não somente o esforço repetitivo, mas principalmente má postura, mobiliário inadequado, fatores ambientais e outros. Assim, os DORT não é resultante somente de um fator, mas de uma série de fatores interligados que geram a queda na produtividade, até a incapacidade funcional.

Analisar o risco é analisar a situação que o produziu e como o trabalhador reagiu ou pode reagir a esta situação. Para Leite (2004), define fator de risco como toda e qualquer situação que coloca o trabalhador a mercê de um possível adoecimento, que pode ser derivada de diversos fatores, como a postura em que o trabalhador é submetido para cumprir as exigências de suas atividades, os movimentos inadequados realizados com uma determinada frequência, mobiliários inadequados que não possibilitem uma permanência confortável do trabalhador durante a jornada de trabalho, fazendo com que ele mesmo procure as adaptações que lhes pareçam mais confortáveis.

\section{Metodologia Aplicada}

Trata-se de um estudo quali-quantitativo, por caracterizarse pelo emprego da quantificação visando à precisão dos resultados evitando distorções de análise e interpretação e, possibilitando, conseqüentemente, uma margem de segurança quanto às inferências e, qualitativo, no qual o pesquisador obtém "medições" que apresentam maior validade interna, pois as observações não estruturadas permitem conhecer detalhes que os instrumentos estruturados (questionários) não podem obter. Partiu-se de uma abordagem descritiva que possibilitou descobrir e classificar a relação entre variáveis e descobrir as características do fenômeno da pesquisa.

Segundo Richardson (1999), nos estudos de natureza descritiva, propõem-se investigar o que é, ou seja, a descobrir as características de um fenômeno como tal. Nesse sentido, são considerados como objeto de estudo uma situação específica, um grupo ou um indivíduo. De uma população de 24 colaboradoras de todo a linha de produção, totalizando $100 \%$ dos trabalhadores deste setor, participaram da amostra 08 colaboradoras do setor de Tecelagem Circular, representando um total de 33,33\% do universo pesquisado, o que significa uma amostra representativa permitindo conhecer com profundidade as possíveis problemáticas encontradas neste posto de trabalho. A entrevista é a técnica que permite o desenvolvimento de uma estreita relação com as pessoas. Para Richardson (1999), "a entrevista pode variar de uma comunicação plenamente bilateral a uma unilateral". Para Marconi \& Lakatos (1999), existem diferentes tipos de entrevistas que variam de acordo com o propósito do entrevistador: "Padronizada ou estruturada: o entrevistador segue um roteiro pré-estabelecido onde às perguntas estão predeterminadas. Despadronizada ou não estruturada: o entrevistado tem liberdade de desenvolver cada situação em qualquer direção que considere adequada. As perguntas em geral são abertas e podem ser respondidas dentro de uma conversação informal. $\mathrm{O}$ entrevistado responde de acordo com o que ele considera os aspectos mais relevantes de determinado problema. Obtêm-se dessa forma informações do entrevistado, conhece opiniões ou atitudes. Painel: consiste na repetição de perguntas, 
de tempo em tempo, às mesmas pessoas, a fim de estudar a evolução das opiniões em períodos curtos".

A técnica de fotos utilizada nesta pesquisa buscou a reprodução fiel das diversas situações observadas através do vídeo institucional e na planta fabril localizada no bairro do Morro da Liberdade em Manaus da Amapoly Indústria e Comércio LTDA. Esta técnica é indispensável para analisar situações complexas. Esta técnica foi realizada para complementação das demais com o intuito de acompanhar o comportamento das colaboradoras em situações de diferentes picos de movimento. Buscou-se, também, realizar os dimensionamentos dos postos de trabalho em que das colaboradoras estão envolvidas e as medidas referentes às condições ambientais (iluminação, ruído, temperatura, velocidade e umidade do ar) no qual estão submetidos. Utilizouse de um questionário em Anexo I baseado no Check List de Couto (2000) com questões fechadas, referentes às necessidades do presente trabalho. Para o auxílio da confecção do questionário o autor auxiliou-se dos seguintes questionários descritos por Miranda \& Dias (1998), para avaliar as condições ergonômicas e organizacionais e o Questionário Nórdico Padronizado para Análise dos Sintomas Músculo-Esqueléticos (CHAFFIN \& ANDERSONN, 2001).

$\mathrm{O}$ instrumento foi subdividido em cinco partes: $\mathrm{O}$ primeiro trata de um formulário contendo 11 perguntas de Análise Ergonômica: Com data, Unidade, Área, Linha e $\mathrm{n}^{\circ}$, Equipamento/Máquina, Título do problema/preocupação ergonômica contendo: Descrição da tarefa, principais aspectos de dificuldades referidos pelas colaboradoras, sequência de ações técnicas e risco ergonômico suspeito: Descrição da atividade, riscos ergonômicos suspeitos, partes do corpo, gravidade AMB e solução. Fatores complementares: posturas para trabalhar, método/turno, tempo de ciclo, ritmo, taxa de ocupação, tempo de trabalho, ambiente. Evidências. Identificador. Instrumentos de Avaliação Complementar. Conclusão quanto ao risco ergonômico. Critério de Prioridade. Medida de melhoria ergonômica. Medidas visando o controle do risco ergonômico. A segunda parte, apresenta o Check List de Couto - Versão Dezembro/2000, Contendo 6 perguntas e subitens da Avaliação Simplificada do fator Biomecânica nos Riscos para Distúrbios Músculos-Esqueléticos de Membros Superiores Relacionados ao Trabalho: Sobrecarga Física, Força com as Mãos, Postura no Trabalho, Posto de Trabalho, Repetitividade e Organização do Trabalho, Ferramenta de Trabalho e Critério de Interpretação. A terceira parte apresenta Índice de Sobre Carga Biomecânica. Os dados demográficos considerando-se as variáveis idades, sexo, altura e peso, buscando traçar o perfil do universo estudado; na segunda, consta o dado referente às questões ergonômicas e organizacionais do trabalho composto por 17 perguntas, objetivando conhecer individualmente as condições atuais de realização das suas atividades, considerando a aspectos técnicos (máquinas, layout, mobiliário), aspectos organizacionais (divisão do trabalho, o número e a duração das pausas, trabalho em turnos, ritmo de trabalho, etc) e, ainda, os aspectos posturais; e, a terceira, busca avaliar as condições de trabalho através de seis (06) questões com a finalidade de obter os dados relativos às condições favoráveis ou desfavoráveis aos usuários; as quartas abordam questões referentes às condições ambientais compostas por seis 06 perguntas, considerando-se os níveis de ruído, temperatura, luminosidade, vibração e toxicologia do ar; e a quinta, trata da avaliação das condições físicas com 2 perguntas, objetivando identificar a origem dos possíveis problemas, os movimentos ou posturas adotados ou realizados com maior grau de dificuldades, condições músculos-esqueléticos, apresentação de algias (dores), e qual ou quais os locais do corpo que apresentam algum tipo de acometimento para verificar se há correlação com a atividade realizada.

Através do questionário procurou-se obter informações qualitativas e quantitativas sobre as reais situações em que das colaboradoras de produção executam suas atividades (ergonômicas ambientais e organizacionais). Com o instrumento previamente elaborado, aplicou-se um teste piloto a uma amostra de 08 voluntárias, para comprovar a efetividade do mesmo, diminuindo assim a margem de erros. Após a aprovação, aplicouse o questionário definitivo. "A análise documental é uma série de operações que visam estudar e analisar um ou vários documentos para descobrir as circunstâncias sociais e econômicas com as quais podem estar relacionados". Trabalha diretamente sobre os documentos e o objetivo básico é a determinação fiel dos fenômenos sociais", (RICHARDSON, 1999). Caracteriza-se como a fase da pesquisa que tem o intuito de recolher informações sobre o campo de interesse. "O levantamento de dados é o passo inicial de qualquer pesquisa científica podendo ser feito através da pesquisa documental (ou fontes primárias) e pesquisa bibliográfica (ou fontes secundárias)" (MARCONI \& LAKATOS, 1999).

$\mathrm{Na}$ pesquisa documental, a fonte de coleta de dados está restrita a documentos, escritos ou não, constituindo as fontes primárias, os quais podem ser recolhidos no momento em que os fatos ocorrem ou depois. Considera-se documento qualquer informação em forma de texto, imagens, sons, sinais em papel/madeira, gravações, pinturas e outros. "Podem ainda ser classificado como documentos oficiais (editoriais, leis, atas, relatórios etc.) e documentos jurídicos oriundos de cartórios, inventários, testamentos, escrituras, atestados de nascimentos, óbitos e outros" (FACHIN, 2001).

\section{Apresentando o Estudo de Caso}

A Empresa Amapoly Indústria e Comércio Ltda, está localizada no estado do Amazonas, Zona Sul da Cidade de Manaus, na Rua São Benedito, $\mathrm{n}^{\circ} 170$ Bairro Morro da Liberdade, possui área construída de $10.095,99 \mathrm{~m}^{2}$, atualmente dispõe de 285 colaboradores efetivos, distribuídos em turnos de trabalho (matutino, vespertino e noturno). Tendo como ramo de atividades composto na fabricação de LONAS E COBERTURAS (LAMINADOS). Pertencem ao Grupo empresarial SÀO PAULO ALPARGATAS S.A. e CAMARGO CORREA S.A.. Funcionando há 33 anos na capital amazonense, é a fábrica do grupo São Paulo Alpargatas responsável pela unidade de negócio têxtil, produzindo dentre outros tipos de laminados, lonas para agroindústria; para o mercado marítimo; laminados para banners; projeção de imagens; coberturas solares. 
A fábrica possui em seu quadro de colaboradores atuando em diversificados setores da unidade de negócio, entre a Administração, RH, Produção, Engenharia de Manutenção. Funcionando 24 horas em turnos de 8 horas de trabalho diário, a Amapoly possui uma produção pronta e apta para atender a demanda de todo o território nacional, visando com isso, dentro da elaboração de todo um planejamento estratégico, futuramente atender o mercando internacional e tentar colocar o Brasil no cenário das indústrias têxtil internacional produtores de lonas e laminados. A empresa mantém, dentre outras conquistas, a certificação NBR ISO 9001:2000 para garantir e assegurar ainda mais, a qualidade de seus produtos e manter a confiabilidade de seus clientes.

\subsection{Levantamento de Dados com relação à Biomecânica Postural}

Para a melhor compreensão sobre os mecanismos posturais e sua manutenção perante as situações exigidas no trabalho e na vida cotidiana aponta as interações entre o trabalho e a colaboradora sob o ponto de vista dos movimentos músculoesqueléticos envolvidos das colaboradoras do Setor de Tecelagem Circular.

O estudo analisa a questão das posturas corporais no trabalho e a aplicação de forças. Faz referência ao manuseio nos equipamentos dos postos críticos de trabalho e instalações físicas, que se forem inadequadas e realizadas biomecanicamente incorretas, podem ser motivo para o surgimento de tensões musculares, dores e fadiga como mostra as Figuras 1.
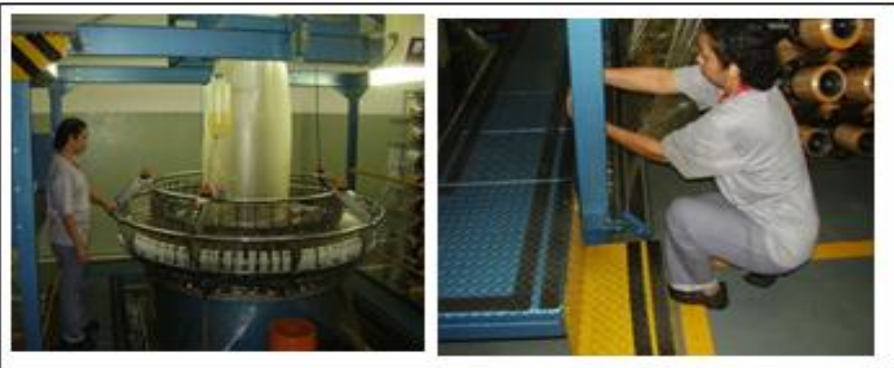

Figura 1: Mostra a colaboradora iniciando suas atividades.

Os princípios mais importantes da biomecânica para a Ergonomia. No caso das colaboradoras da Amapoly Indústria e Comercio LTDA ressalta que as articulações devem ocupar uma posição neutra; conservar pesos e flexões próximos ao corpo; evitar curvar-se para frente; evitar inclinar a cabeça; evitar torções de tronco e movimentos bruscos que produzem picos de tensão; alternar posturas e movimentos; restringir a duração do esforço muscular contínuo; prevenir a exaustão muscular e opção por pausas curtas e frequentes por se tratar de uma atividade onde as colaboradoras trabalham em pé durante 8 horas diárias exercendo atividades conforme a Figura 2.

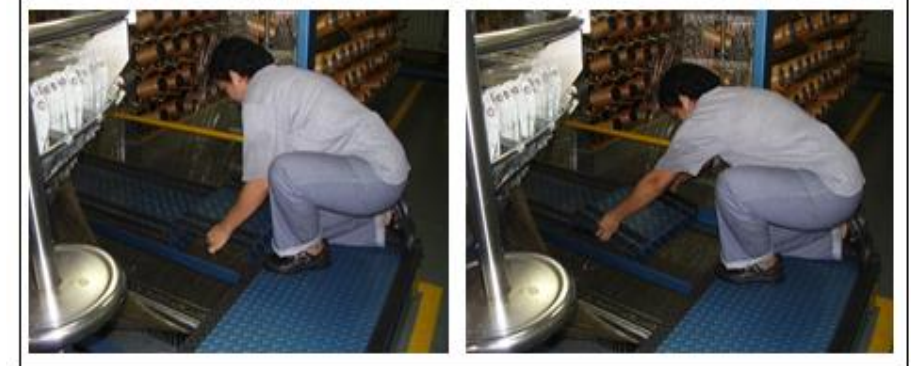

Figura 2: Mostra a colaboradora puxando a base do Piso da Máquina da Tecelagem Circular.

Esse movimento humano é um sistema de comportamento físico marcado por normas, regras e convenções que, na opinião de muitos, adapta as condições em respostas anátomofisiológicas e biomecânicas do corpo e, através de sua estrutura biológica, permite a produção de força através da contração muscular, transformando o corpo num sistema independente possibilitando o movimento. A biomecânica utiliza as leis da física e conceitos de engenharia para descrever os diversos movimentos realizados pelas colaboradoras durante toda a atividade, seja ela profissional ou atividades normais de vida diária, principalmente quanto se refere às atividades onde requer esforço físico demasiado e cujo tempo médio das 14 atividades permitem que se tenha um ciclo de tempo de operação inferior a 40 segundos a Figura 3 mostra exatamente isso sem contar o tempo em que a colaboradora vai buscar as bobinas com fiação.

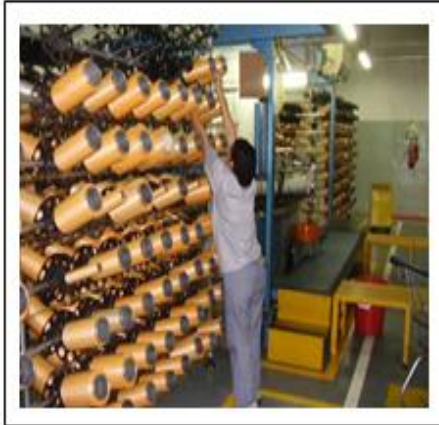

Figura 3: Mostra à colaboradora ajustando a base da Máquina de Tecelagem Circular.

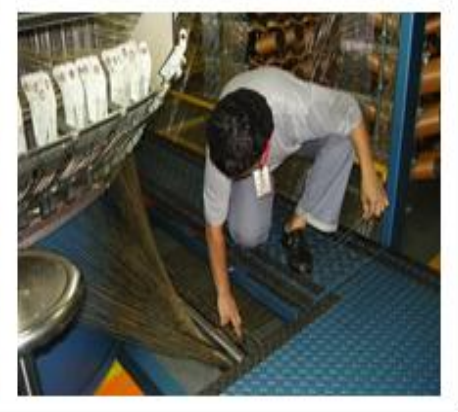

Figura 4: A colaboradora tirando a Bobina.
Neste caso a biomecânica como uma ciência multidisciplinar, deriva dos conhecimentos das ciências físicas, biológicas e comportamentais, além dos conhecimentos sobre a engenharia de processo e dentro dela requer um conhecimento de ergonomia onde as relações de homem x máquina tornam-se mais prazeroso. Observe na Figura 4 à colaboradora se esticando com os membros superiores de forma inadequada e na parte de baixo da Figura 4 mostra de maneira tímida a colaboradora de ponta de pé para alcançar a execução da tarefa. $\mathrm{O}$ trabalho considera que no estudo multidisciplinar, a força que é empregada nos movimentos e/ou atividades se traduz como variável de grande importância, onde os esforços podem ser tanto ocasionais, quanto bastante 
repetitivo. Ambos se realizados demasiadamente, podem levar a um estresse biomecânico, resultando em lesões graves e incapacitantes as colaboradoras atingindo dores nas costas na medida em que esse esforço e repetido por várias vezes durante o ciclo de trabalho.

As estatísticas de lesões ocupacionais indicam que as combinações de traumas por impacto e por esforço excessivo são as causas principais de incapacidade das colaboradoras. Por isto, faz-se necessário o conhecimento minucioso de biomecânica ocupacional para o entendimento do mecanismo da lesão, assim como para traçar estratégias de prevenção que permitam as colaboradoras realizar de forma segura suas tarefas e, acima de tudo, respeitando sua capacidade durante toda a vida laboral, haja vista que nos postos críticos estudados permitiram a análise diante avaliação dos principais aspectos de dificuldades referidos aos problemas ergonômicos como mostra a Figura 5.

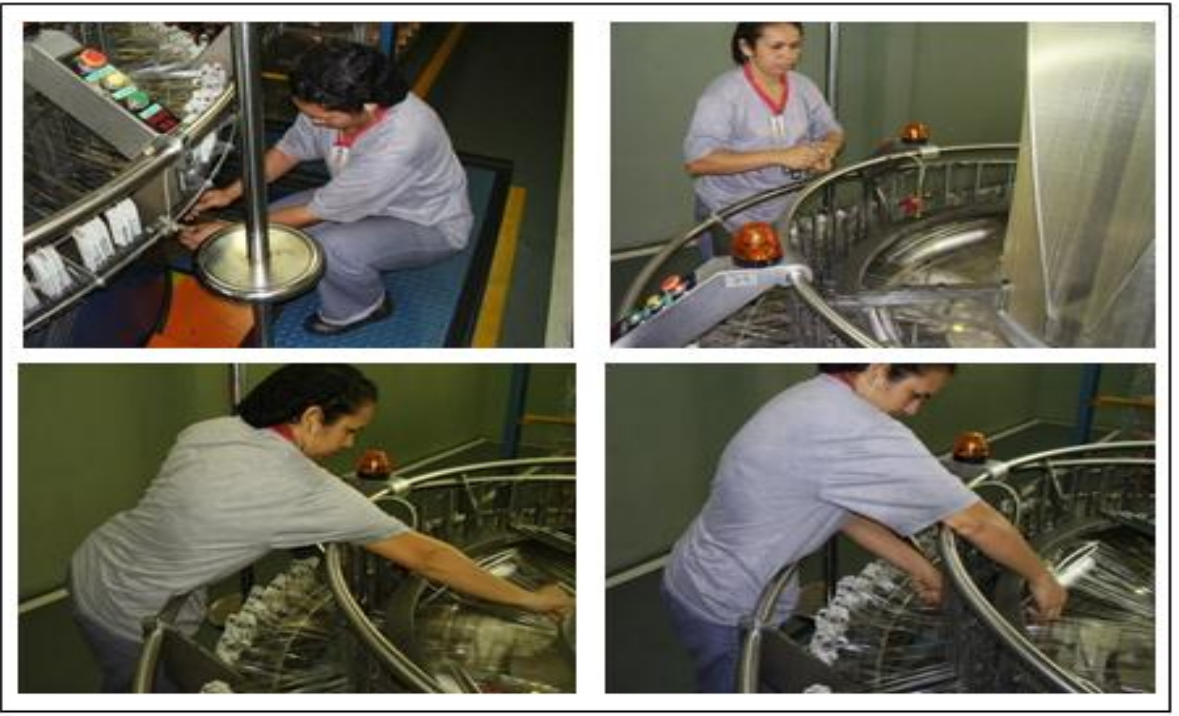

Figura 5: Seqüência de atividades.

A biomecânica ocupacional prioriza a interação física das colaboradoras com suas ferramentas, máquinas e materiais, objetivando a melhora de sua performance e minimização dos riscos de distúrbios músculo-esqueléticos. Os DORT foram reconhecidos e estabelecidos no Brasil, pelo Instituto Nacional de Seguridade Social - INSS no final da década de 90, designado como sendo um conjunto de doenças que atingem músculos, tendões, nervos e vasos dos dedos, das mãos, punhos, antebraços, braços, ombros, pescoço e coluna vertebral. São provocados por atividades profissionais que exigem das colaboradoras movimentos manuais repetitivos, contínuos e de grande intensidade, associados a uma organização do trabalho e equipamentos inadequados (neste caso o equipamento não é inadequado, mas sim a forma como as colaboradoras trabalham no processo devido as suas alturas em média $1,55 \mathrm{~m}$, conforme constatado no posto de trabalho cuja área é muito dimensionada de forma que o torne inadequada para operação).

Os DORT como patologia multifatorial e, devido a isto, há falta de clareza sobre o processo patogênico que segundo as autoridades brasileiras permitem ainda que as colaboradoras sejam lesionadas sem se quer ter o direito de reivindicar uma infraestrutura adequada de trabalho visando assim uma relação de conforto no ambiente de trabalho. Devido a esta falta de clareza sobre o processo patogênico, e devido à multiplicidade dos fatores causais, dentre eles os relacionados ao trabalho, adotou-se o termo distúrbio, no qual os DORT tornou-se ainda mais conhecida. Sendo assim, atualmente refere-se às patologias não mais como lesões, e sim como distúrbios. A combinação dos elementos desencadeadores e da solicitação física resulta no uso abusivo dos músculos e tendões, elevando o risco de lesões quando associados a movimentos rápidos e repetitivos em ação nos quais prevalecem as contrações musculares estáticas e posturas inadequadas. $\mathrm{Na}$ verdade os DORT classificam os fatores de risco como uma desordem músculo-esquelética, advindos de qualquer anormalidade temporária ou permanente do sistema músculo-esquelético resultando em dor ou desconforto. $\mathrm{Na}$ Figura 6 mostra, as posturas inadequadas podem conduzir a problemas músculos-esqueléticos.

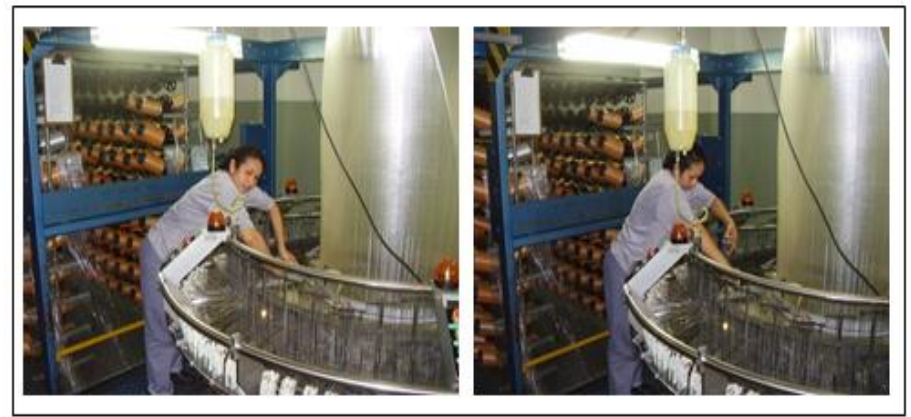

Figura 6: Posição inadequada prejudicando a coluna lombar. 
Tabela 3: Avaliação Quantitativa de Níveis de Iluminância (Lux) - Segurança $\mathrm{N}^{\circ} 03$ - Período Diurno.

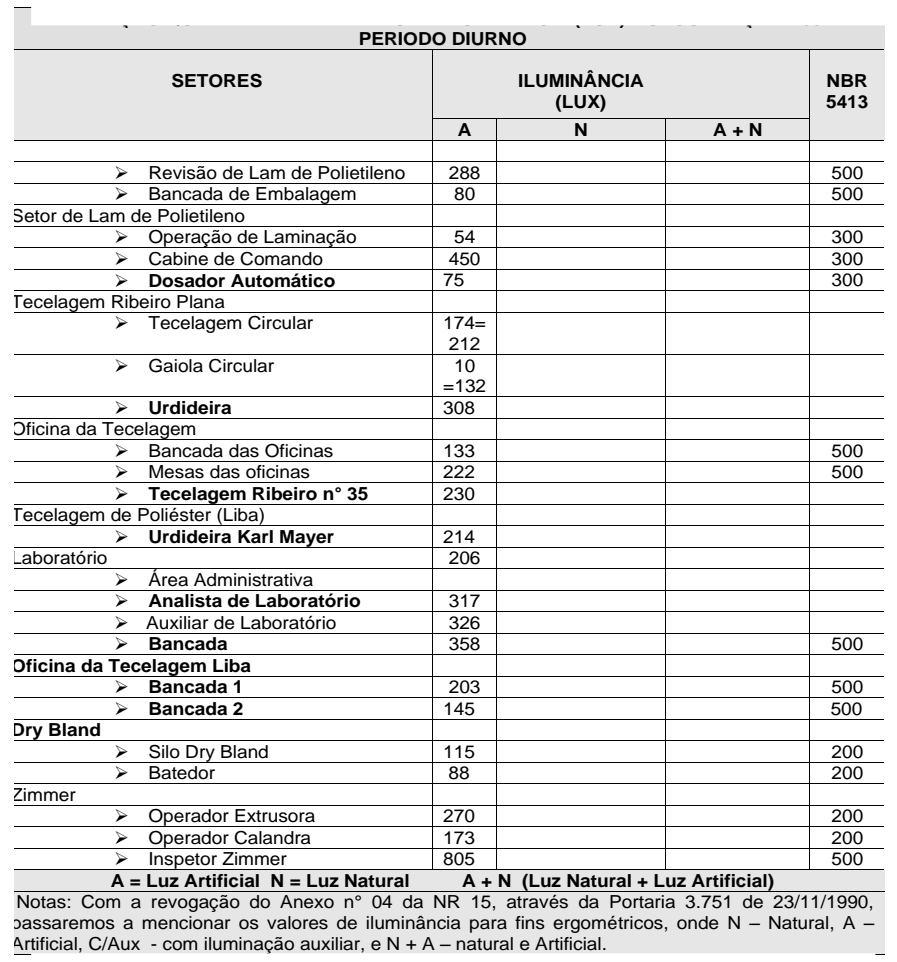

Fonte: Amapoly Indústria e Comercio Ltda, (2013).

Tabela 4: Avaliação Quantitativa de Níveis de Iluminância (LUX) - Segurança n ${ }^{\circ} 03$ Período Diurno.

\begin{tabular}{|c|c|c|c|c|}
\hline \multicolumn{5}{|c|}{$\begin{array}{l}\text { AVALLAÇÃO QUANTITATIVA DE NIVEIS DE ILUMINÂNCIA (LUX) - SEGURANÇA No O3 - } \\
\text { PERIODO DIURNO }\end{array}$} \\
\hline \multirow[t]{2}{*}{ SETORES } & \multicolumn{3}{|c|}{$\begin{array}{l}\text { ILUMINÂNCIA } \\
\text { (LUX) }\end{array}$} & \multirow[t]{2}{*}{$\begin{array}{l}\text { NBR } \\
5413\end{array}$} \\
\hline & A & $\mathrm{N}$ & $A+N$ & \\
\hline \multicolumn{5}{|l|}{ Setor Mesa Revisora } \\
\hline$>$ Inspetor de Qualidade & 514 & & & 500 \\
\hline Auxiliar de Produção & 149 & & & 300 \\
\hline \multicolumn{5}{|l|}{ Setor de Fiação } \\
\hline Area da Betoneira & 134 & & & 200 \\
\hline Fiandeira & 244 & & & 200 \\
\hline \multicolumn{5}{|l|}{ Recuperadora de Polietileno } \\
\hline Area dos Moinhos & 95 & & & 200 \\
\hline \multicolumn{5}{|l|}{ Setor Extrusora } \\
\hline Picotagem & 325 & & & 200 \\
\hline Funil de Alimentaçãa & 328 & & & 200 \\
\hline \multicolumn{5}{|c|}{$A=$ Luz Artificial $N=$ Luz Natural $\quad A+N($ Luz Natural + Luz Artificial) } \\
\hline $\begin{array}{l}\text { Notas: Com a revogaacāo do Anexo } \\
\text { passaremos a mencionar os valores } \\
\text { Artificial, C/Aux - com iluminacăa auxilili }\end{array}$ & & & & $\begin{array}{l}1 / 1990, \\
\text { al, A- }\end{array}$ \\
\hline
\end{tabular}

Fonte: Amapoly Indústria e Comercio Ltda, (2013).

\subsection{Conforto Térmico}

$\mathrm{O}$ ambiente de trabalho mostra as atividades das colaboradoras em um ambiente completamente quente onde ser humano possui certo grau de adaptação tanto a climas quentes quanto a climas frios. Pode-se dizer que nossa possibilidade de autoproteção é maior aos climas frios, porém no trabalho a adaptação ao frio passa necessariamente pelo uso de roupas pesadas e muitas vezes desconfortáveis e limitadores dos movimentos, neste caso as colaboradoras executam suas atividades de trabalho com roupas simples (macacão, botas, tocas, protetor auricular devido aos rú́dos dos equipamentos e em alguns casos luvas). No trabalho em ambientes com temperaturas internas superiores a $40^{\circ} \mathrm{C}$, o organismo passa a ter como uma das prioridades a dissipação do calor corpóreo, perdendo assim uma quantidade significativa de possibilidade de trabalho físico. A adaptação do ambiente de trabalho às características das colaboradoras passa por uma série de medidas que vão desde a pausa de recuperação até a seleção adequada de pessoal. Há uma queixa de calor relatada pelas colaboradoras da Amapoly.

\subsubsection{Características Básicas do Ser Humano Trabalhando em Ambiente Quente}

As colaboradoras são dotadas de um sistema de controle capaz de lhe garantir uma temperatura interna constante mesmo diante de grandes variações de temperatura ambiente. Como as colaboradoras são classificadas como um animal homeotérmico, ou seja, a temperatura do seu sangue praticamente não se altera. Segundo Leite (2004), desde que adequadamente protegido, o homem consegue tolerar bem variações de $-50^{\circ}$ até $100^{\circ}$ Centígrados. No entanto, apesar dessa faixa de tolerância, assusta-nos saber que essa mesma colaboradora não tem condições de tolerar variações de $4^{\circ} \mathrm{C}$ na sua temperatura interna sem que ocorra o comprometimento da capacidade física e mental e risco de vida. Caso a temperatura interna (do sangue que chega ao cérebro) aumente significativamente (acima de $42^{\circ}$ centígrados), corre-se o risco de haver a desnaturação das proteínas orgânicas (estado em que as proteínas não são destruídas, mas têm seu estado coloidal alterado), e que teria como consequência a morte. No outro extremo, caso a temperatura do corpo baixasse excessivamente (abaixo de $33^{\circ} \mathrm{C}$ ), as enzimas corpóreas teriam seu efeito inibido, o que na prática também corresponde ao óbito. É mais difícil para as colaboradoras se adaptarem a altas temperaturas do que às baixas temperaturas.

A adaptação a altas temperaturas apresenta um problema especial: a própria atividades energéticas das colaboradoras são de baixíssimo rendimento, ou em outras palavras, produz muito calor interno. Assim, qualquer ambiente de altas temperaturas pode gerar distúrbios orgânicos, o que não ocorre facilmente nos ambiente de baixas temperaturas.

Quanto mais intenso for o trabalho, tanto menor será a tolerância das colaboradoras ao ambiente quente; quanto mais quente o ambiente de trabalho, tanto menor a tolerância da colaboradora à atividade física e mental. Como o trabalho no processo de produção da Amapoly não relacionado a ambientes com temperaturas altíssimas, ruídos não apresentaremos uma análise mais detalhada do caso. 
Jandecy Cabral Leite et al./ ITEGAM-JETIA Vol. 01, N 02, pp.22-37. Junho, 2015.

4.4 Análise de Resultados nos Processos de Avaliação para Prevenção de Riscos Ergonômicos nos Postos Críticos de Trabalhos

\section{* Quanto a Biomecânica Postural ao Risco Ergonômico}

Sabendo-se que a Ergonomia tem por objetivo adequar o trabalho às características das colaboradoras, sejam físicas, sejam psíquicas, é necessário que tenhamos conhecimentos mínimos de como nosso organismo funciona e quais são as limitações do nosso corpo, para que possa desenvolver projetos que correspondam a tais características. $\mathrm{Na}$ análise postural, verificamos um exemplo de como é importante para a colaboradora conhecer as limitações do seu corpo e como este pode se sobrecarregar, com o intuito de buscar soluções para os problemas diagnosticados:

* Nas atividades encontradas, verificou-se que a colaboradora, apesar de trabalhar numa postura variada, mas na sua maioria em pé, sentia fortes dores nas costas, ombros, punho esquerdo, bem como sentia dormência na parte inferior das pernas e pés por trabalhar durante 8 horas diárias basicamente em pé e muitas vezes fazendo flexão buscam no sentido de adequar as alturas para realizar suas tarefas. Feridas na altura dos joelhos foram encontradas em nos relatos de algumas colaboradoras acontecidas no período de experiência das atividades no setor e dores de cabeça também foram constatadas. Comentou-se que as dimensões do posto de trabalho encontravam-se inadequadas, bem como a especificação da linha de produção, ferramentas dentre outros problemas.

* Constatou-se que amortecimento de forças cuja finalidade é desempenhada pelos discos interveterbrais, que já conhecemos. Nas reclamações das colaboradoras mostraram que os discos promovem uma proteção essencial às vértebras, na medida em que impedem que estas sofram fraturas e dores por todo o corpo. São também os discos que promovem a ligação fibrosa entre todas as vértebras, uma a uma, auxiliando que a coluna se torne uma estrutura rígida, quando assim o desejamos, ou flexível, quando necessário.

* O amortecimento das pressões exercidas sobre o conjunto é desempenhado essencialmente pelos núcleos pulposos (NP's), que distribuem radialmente a pressão recebida. Isto equivale a dizer que o núcleo, que se encontra dentro dos anéis, tende sempre a aumentar seu diâmetro quando recebe a carga de cima para baixo, fazendo pressão sobre as paredes dos anéis que o envolvem, enquanto diminui de altura, isso foram mostrados nas figuras apresentadas no levantamento de dados e Biomecânica Postural. O resultado desta análise mostra que o disco intervertebral apresenta uma degeneração natural que se acentua a partir dos 20 anos de idade (faixa etária das colaboradoras dos postos críticos estudados são em média 26 anos), época em que as artérias que alimentam a região da coluna vertebral começam a se fechar, interrompendo a vaso-irrigação e, claro, sua alimentação como foram relatados nos questionários respondidos pelas colaboradoras.

* Assim, o disco passa a receber alimentação de líquidos nutrientes que se encontram na região, principalmente aqueles que permanecem no tecido esponjoso que reveste as faces superiores e inferiores dos corpos vertebrais. Contudo, claro está que quando a coluna recebe uma carga sobre o conjunto de vértebras, o líquido será expulso da região na qual se encontra naturalmente, dada a pressão ali concentrada. O comportamento é similar a uma esponja.

* Tal fato é muito importante, vez que podemos concluir que, pressionada, a coluna vertebral não se alimenta e que tal situação facilita ainda mais a degeneração dos discos intervertebrais. Sem alimentação, a característica fibroelástica destes tende a diminuir, o que inicia um processo de rompimento das paredes dos anéis que envolvem o NP, toda vez que este tenta se deslocar de sua origem.

* A função de amortecimento, pois, vai diminuindo à medida que a idade do indivíduo aumenta. Situações agudas, que promovem rompimento repentino de grande número de anéis fibrosos, causam lesões que serão comentadas mais adiante. Por isso é importante criar uma cultura entre as colaboradoras, onde possam apresentar os fatores complementares tais como: postura para trabalhar, utilizar diferença de método, analisar o tempo de ciclo, para verificar se é compatível ou não, a existência de ações técnicas distintas no ciclo de trabalho, ritmo de trabalho, taxa de ocupação, tempo de trabalho e alternância de tarefas para evitar esforço repetitivo e verificar o número de operações por turno/ número de movimentos repetitivos por turno e conseqüentemente por atividades diárias e o ambiente de trabalho considerando a iluminação, ruído, conforto térmico entre outros.

* A região cervical das colaboradoras apresenta a maior mobilidade (flexibilidade) de todo o sistema, seguida pela região lombar e dorsal, até atingirmos a região sacrococcigeana, que apenas rotaciona sobre o eixo da cintura pélvica prejudicando as colaboradoras nas suas atividades normais.

* A mobilidade do conjunto, entretanto, representa não apenas flexibilidade útil para desenvolvê-lo de inúmeras tarefas efetuadas pelas colaboradoras, mas alguns riscos à região da coluna vertebral.

* Tais posturas das colaboradoras apresentadas no trabalho serão causas do aparecimento dos DORT como Hérnia de Disco, Bico de Papagaio, Cintura Escapular, Cintura Pélvica, Membros Superiores e Inferiores, bem como doenças de Articulação.

Quanto ao risco ergonômico é de extremamente importante que se considere não apenas as ações técnicas inadequadas sob o ponto de vista ergonômico, mas também a existência de mecanismos de regulação encontradas no meio fabril da Amapoly. Tais mecanismos de regulação eficientes considerados de baixa freqüência da operação crítica ao longo do turno, principalmente no noturno, que é o mais comum, neste caso geralmente anulam o risco ergonômico de ações técnicas feitas em condições desfavoráveis.

É também importante avaliar a potencialização do risco ergonômico pelos fatores de organização do trabalho e pelos 
fatores de natureza psicossocial encontrados na Amapoly. No Quadro II-1 mostra uma série de ações técnicas e situações em que consideradas Hazard, risco leve a moderado e em alto risco. Ao se descrever o risco, deve-se classificá-lo, considerando a gravidade, a (s) parte (s) dos corpos susceptíveis e quais os fatores causados do mesmo. De acordo com o Check List de Couto (2000), apresenta-se o resultado da pesquisa com um universo de 08 colaboradoras de linha de produção com as seguintes características:

1. Sobrecarga Física: As respostas das colaboradoras foram os seguintes: $37,5 \%$ disseram NÃO e $25 \%$ disseram SIM.

2. Força Com as Mãos: As colaboradoras apresentam uma resposta de $100 \%$ das perguntas. O que representa uma preocupação como posto de trabalho.

3. Postura no Trabalho: $100 \%$ das colaboradoras estão bastante preocupadas com a performance do setor, onde o grau de incidência ocorrido durante a jornada de trabalho caracterizam o esforço permanente no trabalho.

4. Posto de Trabalho: $87,5 \%$ apresentam preocupação com o setor, uma vez as situações encontradas não permitem flexibilidades no posicionamento das ferramentas, nem pouco com a inclinação dos objetos localizados nas máquinas como mostra nas figuras.

5. Repetitividade e Organização no Trabalho: $100 \%$ das entrevistadas responderam SIM, o que caracterizam um esforço físico para realização das tarefas um pouco tempo numa jornada de 8 horas diárias apresentando uma alternância entre trabalhar em pé e as flexibilidades de se agachar para realizar suas tarefas. 6. Ferramenta de Trabalho: Não foi respondido por não se adequarem com a realidade de trabalho.

No Quadro 2 mostra Classificação de Movimentos, Posturas e Outros Fatores Quanto ao Risco Ergonômico e as dicas padronizadas através de atividades científicas realizadas no Brasil. Segue o modelo de Couto (2002) como referencia por se adaptarem na maioria das atividades encontradas no meio fabril brasileiro e em especial na Amapoly Industria e Comercio LTDA.

Quadro 2: Classificação de Movimentos, Posturas e Outros Fatores quanto ao Risco Ergonômico.

\begin{tabular}{|c|c|c|c|c|}
\hline \multicolumn{5}{|c|}{ Classificação de Movimentos, Posturas e Outros Fatores Quanto ao Risco Ergonômico. } \\
\hline Parte do & Ação Técnica Normal & Hazard & Risco & Alto Risco \\
\hline \multirow[t]{2}{*}{ Olhos } & $\begin{array}{l}\text { Visão para longe/Visão } \\
\text { para perto alternada com } \\
\text { visão para longe. }\end{array}$ & $\begin{array}{l}\text { Manutenção de fixação } \\
\text { visual para perto, com pausas } \\
\text { bem definidas ou com } \\
\text { atividades de descanso } \\
\text { rotineiras. }\end{array}$ & $\begin{array}{l}\text { Manutenção de fixação } \\
\text { visual para perto como } \\
\text { rotina de trabalho, sem } \\
\text { pausas definidas. }\end{array}$ & $\begin{array}{l}\text { Fixação visual com } \\
\text { peça } \\
\text { movimento. }\end{array}$ \\
\hline & & & $\begin{array}{l}\text { Claridade incidindo } \\
\text { diretamente ou por } \\
\text { reflexo nos olhos }\end{array}$ & \\
\hline Pescoço & & & $\begin{array}{l}\text { Posicionamento } \\
\text { estático. } \\
\text { Posicionamento } \\
\text { Estático acima da } \\
\text { horizontal dos olhos. }\end{array}$ & \begin{tabular}{l}
\multicolumn{3}{l}{ Posicionamento } \\
estático fletido \\
entre 45 e 75 graus.
\end{tabular} \\
\hline \multirow[t]{3}{*}{$\begin{array}{c}\text { Ombros e } \\
\text { Braços }\end{array}$} & $\begin{array}{l}\text { Elevação até o nível dos } \\
\text { ombros, ação e volta ao } \\
\text { ponto neutro. }\end{array}$ & $\begin{array}{l}\text { Idem, menos que } 1000 \text { vezes } \\
\text { por turno, esforço fácil. }\end{array}$ & $\begin{array}{l}\text { Elevação acima do } \\
\text { nível dos ombros, mais } \\
\text { que } 1000 \text { vezes por } \\
\text { turno, ações técnicas } \\
\text { rápidas; ou pelos } \\
\text { menos de } 1000 \text { vezes } \\
\text { por turno, porém ações } \\
\text { técnicas difíceis. }\end{array}$ & $\begin{array}{l}\text { Elevação acima do } \\
\text { nível dos ombros, } \\
\text { mais de } 1000 \text { vezes } \\
\text { por turno e ações } \\
\text { difíceis ou } \\
\text { prolongadas. }\end{array}$ \\
\hline & Abdução até 45 graus & Abdução 45 a 90 graus & $\begin{array}{ll}\begin{array}{l}\text { Sustentação } \\
\text { abdução sem força }\end{array} & \text { em } \\
\end{array}$ & $\begin{array}{l}\text { Sustentação em } \\
\text { abdução com força. }\end{array}$ \\
\hline & $\begin{array}{l}\text { Movimentos dentro da } \\
\text { área de alcance normal }\end{array}$ & $\begin{array}{l}\text { Movimento dentro da área de } \\
\text { alcance máximo (menos de } \\
1000 \text { vezes por turno) }\end{array}$ & $\begin{array}{l}\text { Movimento freqüente } \\
\text { dentro da área de } \\
\text { alcance máximo (mais } \\
\text { de } 1000 \text { vezes por } \\
\text { turno). } \\
\text { Qualquer movimento } \\
\text { com os braços que } \\
\text { exija força excessiva } \\
\text { ocasionalmente. }\end{array}$ & $\begin{array}{l}\text { Movimento } \\
\text { freqüente além da } \\
\text { área de alcance } \\
\text { máximo } \\
\text { Movimento dentro } \\
\text { da área de alcance } \\
\text { exercendo força } \\
\text { elevada para se } \\
\text { empurrar peças } \\
\text { contra resistência, } \\
\text { causando impacto } \\
\text { sobre os ombros }\end{array}$ \\
\hline
\end{tabular}


Jandecy Cabral Leite et al./ ITEGAM-JETIA Vol. 01, Nº 02, pp.22-37. Junho, 2015.

\begin{tabular}{|c|l|l|l|l|}
\hline \multicolumn{1}{|c|}{} & & & & $\begin{array}{l}\text { e/ou cotovelos. } \\
\text { Qualquer } \\
\text { movimento } \\
\text { exija que } \\
\text { emprego de } \\
\text { excessiva } \\
\text { força } \\
\text { constantemente. }\end{array}$ \\
\hline Cotovelos & $\begin{array}{l}\text { Cotovelos em posição } \\
\text { neutra ou fletida sem } \\
\text { sustentação de peso. }\end{array}$ & $\begin{array}{l}\text { Cotovelos fletidos com } \\
\text { sustentação de pesos } \\
\text { ocasionalmente. }\end{array}$ & $\begin{array}{l}\text { Cotovelos fletidos com } \\
\text { sustentação de pesos } \\
\text { freqüentemente. }\end{array}$ & $\begin{array}{l}\text { Cotovelos fletidos } \\
\text { com sustentação de } \\
\text { peso elevado e } \\
\text { esforço estático } \\
\text { constante. }\end{array}$ \\
\hline
\end{tabular}

Fonte: Couto, (2002).

Quadro 2.1: Continuação: Classificação de Movimentos, Posturas e Outros Fatores Quanto ao Risco Ergonômico.

\begin{tabular}{|c|c|c|c|c|}
\hline \multicolumn{5}{|c|}{ Classificação de Movimentos, Posturas e Outros Fatores Quanto ao Risco Ergonômico. } \\
\hline Parte do & Ação Técnica Normal & Hazard & Risco & Alto Risco \\
\hline \multirow[t]{2}{*}{ Antebraços } & $\begin{array}{l}\text { Trabalho na posição neutra } \\
\text { Trabalho estático, porém } \\
\text { com apoio. }\end{array}$ & $\begin{array}{l}\text { Trabalho em } \\
\text { pronação }\end{array}$ & 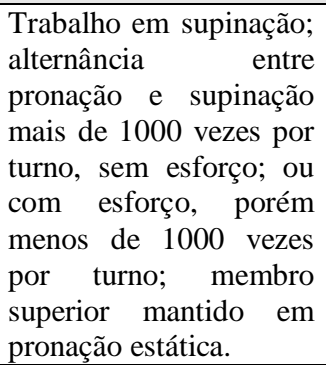 & $\begin{array}{l}\text { Alternância entre pronação } \\
\text { e supinação mais de } 1000 \\
\text { vezes por turno e com } \\
\text { esforço. }\end{array}$ \\
\hline & $\begin{array}{l}\text { Antebraços apoiados sobre } \\
\text { superfície arredondada ou } \\
\text { macia. }\end{array}$ & $\begin{array}{l}\text { Antebraços } \\
\text { encostados em } \\
\text { quinas vivas } \\
\text { ocasionalmente. }\end{array}$ & $\begin{array}{l}\text { Antebraços tendo que } \\
\text { trabalhar apoiados em } \\
\text { quinas vivas. }\end{array}$ & \\
\hline \multirow{3}{*}{ Mãos } & $\begin{array}{l}\text { Mão exerce a função de } \\
\text { agarrar (preensão) e solta } \\
\text { longo em seguida. }\end{array}$ & $\begin{array}{l}\text { Mão } \quad \text { como } \\
\text { morsa, com } \\
\text { mecanismos de } \\
\text { regulação. }\end{array}$ & $\begin{array}{l}\text { Mãos como morsa, sem } \\
\text { mecanismos de } \\
\text { regulação. } \\
\text { Pressão com força } \\
\text { excessiva, ocasional. }\end{array}$ & $\begin{array}{l}\text { Mão como morsa, em } \\
\text { esforço intenso. }\end{array}$ \\
\hline & Pinça sem esforço & $\begin{array}{l}\text { Pinça } \quad \text { com } \\
\text { esforço, porém } \\
\text { com mecanismo } \\
\text { de regulação. }\end{array}$ & $\begin{array}{l}\text { Pinça com esforço, de } \\
\text { forma prolongada. }\end{array}$ & \\
\hline & $\begin{array}{l}\text { Repetição do mesmo } \\
\text { movimento menos que } 1000 \\
\text { vezes por turno. }\end{array}$ & $\begin{array}{l}\text { Repetição do } \\
\text { mesmo } \\
\text { movimento de } 1 \\
\text { a } 3 \text { mil vezes } \\
\text { por turno, com } \\
\text { rodízio ou } \\
\text { pausas. }\end{array}$ & $\begin{array}{l}\text { Repetição do mesmo } \\
\text { movimento de } 1 \text { a } 3 \text { mil } \\
\text { vezes por turno, com } \\
\text { força ou posturas } \\
\text { incorretas, mesmo com } \\
\text { rodízio e pausas. }\end{array}$ & $\begin{array}{l}\text { Repetição do mesmo } \\
\text { movimento mais de } 6000 \\
\text { vezes por turno; Repetição } \\
\text { do mesmo movimento entre } \\
3000 \text { e } 6000 \text { vezes por } \\
\text { turno, exercendo força ou } \\
\text { com posturas incorretas. }\end{array}$ \\
\hline $\begin{array}{c}\text { Postura para } \\
\text { o Trabalho }\end{array}$ & $\begin{array}{l}\text { Trabalhar em posturas } \\
\text { alternadas, sentado e em pé. }\end{array}$ & $\begin{array}{l}\text { Trabalhar } \\
\text { sentado, com } \\
\text { pouca } \\
\text { alternância. } \\
\text { Trabalhar de pé, } \\
\text { com } \\
\text { possibilidade de } \\
\text { regulação. } \\
\text { Trabalho de } \\
\text { cócoras } \\
\text { ocasionalmente. }\end{array}$ & $\begin{array}{l}\text { Trabalhar de pé, parado, } \\
\text { durante a maior parte da } \\
\text { jornada. Trabalhar } \\
\text { sentado durante muito } \\
\text { tempo (mais de } 6 \text { h/dia). } \\
\text { Trabalhar sentado, } \\
\text { estático. Postura de } \\
\text { cócoras com } \\
\text { movimentação do } \\
\text { corpo. Trabalho de } \\
\text { cócoras constante. } \\
\text { Trabalhar deitado com } \\
\text { os braços elevados, } \\
\text { ocasionalmente. }\end{array}$ & $\begin{array}{l}\text { Trabalho sentado durante a } \\
\text { maior parte da jornada, em } \\
\text { cadeira em mais condições. } \\
\text { Trabalho de cócoras com } \\
\text { deslocamento do corpo. } \\
\text { Trabalho deitado com os } \\
\text { braços elevados } \\
\text { constantemente. Trabalho } \\
\text { com torção do corpo, } \\
\text { constantemente. }\end{array}$ \\
\hline
\end{tabular}

Fonte: Couto, (2002). 
Jandecy Cabral Leite et al./ ITEGAM-JETIA Vol. 01, Nº 02, pp.22-37. Junho, 2015.

Quadro 2.2: Continuação: Classificação de Movimentos, Posturas e Outros Fatores Quanto ao Risco Ergonômico.

\begin{tabular}{|c|c|c|c|c|}
\hline \multicolumn{5}{|c|}{ Classificação de Movimentos, Posturas e Outros Fatores Quanto ao Risco Ergonômico. } \\
\hline Parte do Corpo & Ação Técnica Normal & Hazard & Risco & Alto Risco \\
\hline $\begin{array}{c}\text { Postura para o } \\
\text { trabalho }\end{array}$ & & & $\begin{array}{lr}\text { Trabalhar em postura } \\
\text { de torção do corp[o } \\
\text { ocasionalmente, } \\
\text { mecanismo } \\
\text { regulação } \\
\text { manutenção). }\end{array}$ & $\begin{array}{l}\text { Trabalhar em postura } \\
\text { de torção do corpo } \\
\text { constantemente. }\end{array}$ \\
\hline \multirow[t]{3}{*}{ Eixo do Corpo } & Corpo na posição vertical & $\begin{array}{l}\text { Inclinação ocasional } \\
\text { de tronco }\end{array}$ & $\begin{array}{l}\text { Tronco encurvado até } \\
60 \text { graus por algum } \\
\text { período da jornada. } \\
\text { Torção do tronco, sem } \\
\text { flexão com pesos } \\
\text { moderados } \\
\text { pesados, ou } \\
\text { freqüentemente. }\end{array}$ & $\begin{array}{l}\text { Permanência de tronco } \\
\text { encurvado durante boa } \\
\text { parte da jornada de } \\
\text { trabalho. } \\
\text { Torção do tronco e } \\
\text { flexão da coluna, } \\
\text { tendo que manusear ou } \\
\text { levantar pesos, mesmo } \\
\text { que leves. }\end{array}$ \\
\hline & $\begin{array}{l}\text { Sentado, encostado na } \\
\text { cadeira, ângulo de } 90 \text { a } 100 \\
\text { graus. }\end{array}$ & & $\begin{array}{l}\text { Sentado, com tronco } \\
\text { em postura estática (ou } \\
\text { seja, sem apoio para as } \\
\text { costas). }\end{array}$ & \\
\hline & $\begin{array}{l}\text { Sentado, objetos na área de } \\
\text { alcance, inclusive ao pegar a } \\
\text { peça na esteira. }\end{array}$ & $\begin{array}{l}\text { Objetos fora da área } \\
\text { de alcance, uso } \\
\text { ocasionalmente. }\end{array}$ & $\begin{array}{l}\text { Objetos fora da área } \\
\text { de alcance, uso } \\
\text { freqüente, tendo que } \\
\text { encurvar o tronco para } \\
\text { pegá-los. }\end{array}$ & $\begin{array}{l}\text { Objetos fora da área } \\
\text { de alcance e pesados } \\
\text { (mais de } 2 \mathrm{~kg} \text { ), uso } \\
\text { freqüente. }\end{array}$ \\
\hline $\begin{array}{l}\text { Levantamento } \\
\text { de cargas }\end{array}$ & $\begin{array}{l}\text { Índice de Levantamento }<= \\
0,7(\mathrm{NIOSH})\end{array}$ & $\begin{array}{l}\text { Índice } \quad \mathrm{de} \\
\text { levantamento até } 1,2\end{array}$ & $\begin{array}{lrr}\text { Índice } & \text { de } \\
\text { levantamento } & 1,2 \quad \text { a } \\
2,5 . & \end{array}$ & $\begin{array}{l}\text { Índice de } \\
\text { Levantamento }>2,5 \\
\text { Tronco encurvado } \\
\text { sustentando pesos. }\end{array}$ \\
\hline $\begin{array}{l}\text { Horas de } \\
\text { trabalho em } \\
\text { atividade } \\
\text { repetitiva }\end{array}$ & $\begin{array}{l}\text { Até 8h/dia, com pausas } \\
\text { equivalentes a } 17 \% \text { da } \\
\text { jornada. }\end{array}$ & $\begin{array}{l}\text { Até } 8 \mathrm{~h} / \text { dia, pausas } \\
\text { equivalentes a } 8 \% \text { da } \\
\text { jornada. }\end{array}$ & $\begin{array}{l}\text { Até 8h/dia, pausas } \\
\text { menores que } 8 \% \text { da } \\
\text { jornada (sem pausas) } \\
\text { Ou com pausas } \\
\text { equivalentes a } 8 \% \text {, } \\
\text { porém com horas } \\
\text { extras de até } 8 \mathrm{~h} / \text { mês. }\end{array}$ & $\begin{array}{l}8 \mathrm{~h} / \text { dia e, além disso, } \\
\text { mais que } 8 \mathrm{~h} \text { extras } \\
\text { (continuação } \\
\text { jornada) por mês. }\end{array}$ \\
\hline
\end{tabular}

Fonte: Couto, (2002).

* Quanto a Iluminação

No ambiente de trabalho a iluminação adequada se constitui num dos principais itens para execução da atividade correta e do conforto das colaboradoras. A percepção visual adequada depende da iluminação (qualitativa e quantitativa) e das dificuldades das tarefas encontradas na Amapoly. Para iluminação correta dos ambientes de trabalho, dois fatores foram observados: a intensidade da iluminação (ou iluminamento) geralmente sendo expressa por lux, e a luminância ou brilhança, que na verdade é a sensação de brilho e de ofuscamento percebida pelas colaboradoras a partir de uma fonte luminosa, como por exemplo, uma lâmpada, ou refletida por uma superfície conforme mostra as Tabelas 1, 2, 3 e 4.

Apresentamos como sugestões, a partir das observações e nas respostas obtidas pelo questionário envolvendo das 08 colaboradoras envolvidas no processo de pesquisa. Conseqüências da Iluminação: Queda de rendimento no trabalho; Fadiga Visual.
Foram observados também erros comumente cometidos em fábricas em relação à iluminação dos postos de trabalhos observados apresentado suas conseqüências:

1. Nível insuficiente de Iluminamento - Número de lâmpadas insuficiente perto da máquina de Tecelagem Circular como pode ser observada nas figuras mostradas no estudo de caso;

2. Falta de limpeza das luminárias, reduzindo-se assim sua capacidade de refletir a lux;

3. Iluminação insuficiente para a percepção de pequenos detalhes obriga os mecanismos de convergências e acomodação a funcionarem de forma forçada, com fadiga adquirida pelas colaboradoras da linha de produção;

4. Galpão com construções largas, construídas sem iluminação natural pelo teto, o que poderia permite maior luminosidade, ajudando a clarear o ambiente de trabalho; 
Jandecy Cabral Leite et al./ ITEGAM-JETIA Vol. 01, Nº2, pp.22-37. Junho, 2015.

5. Fossem colocadas as calhas com lâmpadas próximas das máquinas, afim que não fosse permitida sombra no ambiente fabril;

6. Uso exclusivo de lâmpadas de teto nos galpões e nos postos de trabalho.

* Quanto à Temperatura

Ao analisarmos as atividades das colaboradoras e estudando a Avaliação Quantitativa de Níveis de Iluminância (LUX) - Segurança $n^{\circ} 03$ Período Diurno/Noturno foi verificado que o índice estabelecido pela Amapoly difere de alguns itens colocados pelas Tabelas 1, 2, 3 e 4 em relação às NRs que estabelece critérios adotados no meio produtivo equacionando as atividades das colaboradoras dentro do processo fabril. Recomendações para as colaboradoras que trabalham em ambientes considerados quentes:

1. Cumpra rigorosamente os horários determinados para se trabalhar e os horários estabelecidos, bem como os horários determinados para fazer pausas, evitar a prática de forçar o trabalho nas primeiras horas da manhã para maior parte do tempo livre à tarde, pois isso pode ocasionar conseqüências graves;

2. Procurar verificar com o médico da Amapoly sua pressão arterial freqüentemente; caso não haja sinais de pressão alta, a colaboradora pode se beneficiar com a ingestão de uma quantidade um pouco maior de sal (por exemplo, pipoca e amendoim torrado);

3. Beber água fria à vontade, mas evitar beber água gelada;

4. Usar as roupas adequadas que lhe são fornecidas pela Amapoly, inclusive os EPIs;

5. Procurar manter sua forma física, através de ginástica laboral, pois pode facilitar a sua condição de trabalho;

6. Evitar engordar, pois isto irá comprometer muito sua capacidade de trabalhar;

7. Procurar conhecer os sinais precoces de sobrecarga térmica, como tontura, náuseas e câimbras e deixe a área quente quando estes sinais se apresentarem; e,

8. Nunca trabalhe em ambiente quente com febre ou com alguma doença que ocasione a febre.

\section{Conclusões}

O objetivo do trabalho foi Identificar os fatores de riscos que interferem na realização das atividades das colaboradoras, bem como a incidência dos aspectos predisponentes dos DORT. O estudo confirmou a importância da ergonomia na investigação de aspectos relacionados às doenças ocupacionais, mais especificamente os fatores causais dos DORT, e para que exista a prevenção entre as populações de risco é de suma importância que, em primeiro lugar, haja uma conscientização tanto por parte dos empregadores como das colaboradoras. As atividades das colaboradoras como evidenciado na pesquisa, é considerada de risco devido às condições em que realizam suas atividades, sobretudo as posturais. Considera-se necessário à adoção de algumas atitudes corretivas para diminuir ou minimizar o risco de acometimento músculo-esquelético entre as colaboradoras, não só da Amapoly, mas de todo o PIM.

Referente às condições organizacionais, há necessidade de rever os parâmetros como pausas para descanso, revezamento de tarefas e horas extras, para que seja reorganizado de maneira a ser introduzido para que possa ser minimizado ou reduzido à sobrecarga de tarefas e principalmente os efeitos da repetitividade. Sobre as condições ambientais, verificou-se que os níveis de iluminação, ruído, velocidade do ar, temperatura e umidade relativa do ar, encontram-se dentro dos limites estabelecidos pela NR-17, levando em consideração a estação em que foram realizadas as medições conforme Tabelas 1, 2, 3 e 4 e Quadro 1. Tais dados são relevantes, haja vista, que as condições ambientais desfavoráveis causam desconforto, aumentando o risco de acidentes e provocando danos consideráveis à saúde das colaboradoras.

\section{Referências Bibliográficas}

BARREIRA, T. H. C. Um enfoque ergonômico para as posturas de trabalho. Revista Brasileira de Saúde Ocupacional. 1989.

BRITO, J. C. Enfoque de gênero e relação saúde/trabalho no contexto de reestruturação produtiva e precarização do trabalho. Caderno de Saúde Pública. Rio de Janeiro - 2000. p.195-204.

CHAFFIN, D, B; ANDERSSON, G, B, J; MARTIN, B, J. Biomecânica Ocupacional. $3^{\mathrm{a}}$ edição. Belo Horizonte. Ergonomia: 2001.

COUTO, H. A. Como gerenciar a questão das LER/DORT: lesões por esforços repetitivos/distúrbios osteomusculares relacionados ao trabalho. Belo Horizonte: Ergo, 1998.

Ergonomia Aplicada ao Trabalho em 18

Lições. Belo Horizonte: Ergo, 2002.

COURY, H. G. Trabalhando Sentado. $2^{a}$ edição. São Paulo: Editora UFSCAR, 1995. p. 35-56.

CRUZ, L. S. et al. Repercussões da Introdução do sistema de leitura óptica sobre o trabalho do operador. Florianópolis: EDUFSC, $\mathrm{n}^{\circ} 27$. Abril de 2000. Revista de Ciências Humanas. p. 117-136.

CHAFFIN, D, B; ANDERSSON, G, B, J; MARTIN, B, J. Biomecânica Ocupacional. $3^{\mathrm{a}}$ edição. Belo Horizonte. Ergonomia: 2001.

DUL, J. \& WEERDMEESTER, B. Ergonomia Prática. São Paulo: Edgar Blucher, 2004.

FACHIN, Odília. Fundamentos de Metodologia. $3^{\text {a }}$ Edição. São Paulo: Editora Saraiva, 2001. 
FILHO, S. B. S; BARRETO, S. M. Algumas considerações metodológicas sobre os estudos epidemiológicos das lesões por esforços repetitivos (LER). Caderno de Saúde Pública, 14 (3): jul-set. 1998. p. 555-63.

GRANDJEAN, E. Manual de Ergonomia: Adaptando o Trabalho ao Homem. $4^{\text {a }}$ edição. Porto Alegre: Bookman, 1998.

IIDA, Itiro. Ergonomia: Projeto e Produção. Editora Edgard Blucher. USP. São Paulo. SP, 2010.

KNOPLICH, J. Viva bem com a coluna que você tem: Dores nas costas, Tratamento e prevenção. $25^{\text {a }}$ edição. São Paulo: Ibrasa, 1996.

LAVILLE, A. Ergonomia. São Paulo, EPU, Ed. da Universidade de São Paulo, 1977.

LEITE. Jandecy Cabral. Convergência Tecnológica nas Áreas de Telecomunicações como Ferramenta Estratégica ao Desenvolvimento Regional: Uma Visão dos Stakeholders. Dissertação de Mestrado do Programa de Pós-Graduação em Engenharia de Produção e Sistemas da Universidade Federal de Santa Catarina (UFSC). Florianópolis - SC, 2001.

Apostila de Ergonomia do Curso de Especialização de Engenharia de Segurança do Trabalho. Escola Superior de Tecnologia (EST) da Universidade do Estado do Amazonas (UEA). Manaus-AM, 2004.

Apostila de Ergonomia do Curso de Especialização de Engenharia de Segurança do Trabalho. Universidade Gama Filho (UGF). Manaus-AM, 2006.

Apostila de Metodologia Científica e da Pesquisa do Curso de Especialização de Engenharia de Segurança do Trabalho, Mecatrônica Industrial, Processo Industriais de Fabricação Mecânica, Tecnologias do Gás Natural. Escola Superior de Tecnologia (EST) da Universidade do Estado do Amazonas (UEA). Manaus -AM, 2004.

Relatório de Pesquisa: Estudos Ergonômicos Aplicados ao Trabalho em Ambientes Laborais: Um Estudo de Caso da Empresa White Martins. Universidade Paulista (UNIP). Pesquisa Financiada pela Fundação de Amparo a Pesquisa do Estado de São Paulo (FAPESP). São Paulo. SP, 2004/2005.

MEDEIROS, Francisco de Assis da Silva. Guia para Elaboração de Monografias e Artigos Científicos. Instituto de Ensino Superior - CESF-FUCAPI. Manaus - AM, 2006.

MARCONI, Marina de Andrade e LAKATOS, Eva Maria. Técnicas de Pesquisa. São Paulo: Atlas, 1999.

MALCHAIRE, J. Lesiones de Miembros Superiores por Trauma Acumulativo: Estratégias de Prevención. Universidade Católica de Lavaina: Bélgica, 1998.
MAZZONI, C. F.; MARÇAL M. A. Análise dos fatores de risco de LER/DORT dos membros superiores em uma linha de empacotamento de uma indústria farmacêutica. Anais ABERGO, Gramado, 2001.p.1-2.

MIRANDA, C. R; DIAS, C. R. Lesões por esforços repetitivos: uma proposta de ação preventiva. Revista CIPA. Salvador. Maio, 1998. (p.48)

NASCIMENTO, N. M. \& MORAES, R. A.S. Fisioterapia nas Empresas. Taba Cultural. Rio de Janeiro - 2000. p.23-55.

NOGUEIRA, Wallace Roberto Melo. Estudo de Tempo e Métodos. Apostila de Tempo e Métodos do Curso de Engenharia de Produção Elétrica do Instituto de Ensino Superior - CESF-FUCAPI. Manaus - AM, 2005.

PEREIRA, M. G. Epidemiologia Teórica e Prática. $4^{\text {a }}$ Edição. Rio de Janeiro. Guanabara-Koogan, 2000.

PEREIRA. R, E. Fundamentos de ergonomia e fisioterapia do trabalho. São Paulo. Fundacentro: p.33. 2006. 